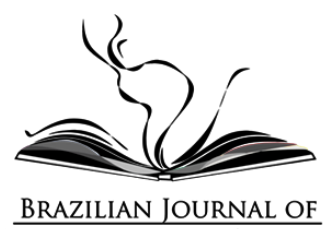

\title{
POBREZA Y CRIMINALIZACIÓN DE LA INFANCIA EN CUBA (1857-1936). REFORMATORIOS PARA MENORES DELINCUENTES Y ESTRATEGIAS BIOPOLÍTICAS
}

\author{
POBREZA E CRIMINALIZAÇÃO DE CRIANÇAS EM CUBA (1857-1936). \\ REFORMATÓRIOS PARA MENORES DELINQUENTES E ESTRATÉGIAS \\ BIOPOLITICAS \\ POVERTY AND CRIMINALIZATION OF CHILDREN IN CUBA (1857-1936). \\ REFORMATORIES FOR JUVENILE OFFENDERS AND BIOPOLITICAL \\ STRATEGIES
}

Javier Ladrón de Guevara Marzal' (i) Universidade Federal de Santa Catarina, Brasil

\author{
Fernanda Martinhago² (it) \\ Université Paris 8 Vincennes-Saint-Denis, France \\ Universidade Federal de Santa Catarina, Brasil \\ Sandra Caponi ${ }^{3}$ (i) \\ Universidade Federal de Santa Catarina, Brasil
}

\begin{abstract}
Resumen: En el siglo XIX Cuba se convirtió en una importante potencia económica, aunque siguió dependiendo de España. Al mismo tiempo que se producían una serie de transformaciones sociales, la delincuencia aumentaba. Es así como, como parte de una estrategia biopolítica, se introdujeron mecanismos de intervención para esa población de indigentes, deambulantes, huérfanos pobres y enfermos mentales, colocados en el imaginario social y en el discurso político e intelectual como responsables de una situación de insalubridad y peligrosidad. Un sector objetivo de esa estrategia fue la infancia pobre, para las que, desde un discurso caritativo, se crearon una serie de instituciones reformatorias. En este artículo analizamos, desde una perspectiva foucaultiana, el funcionamiento de dos de estos espacios: el Asilo San José, que había funcionado hasta el final de la etapa colonial y la Escuela Correccional para varones, creada para reemplazar al anterior, pero con un desempeño similar.
\end{abstract}

\footnotetext{
${ }^{1}$ Estudiante de doctorado del Programa Interdisciplinario en Ciencias Humanas de la Universidade Federal de Santa Catarina. E-mail: javierladronquevara@gmail.com

2 Doctora en Antropología Médica por la Universitat Rovira i Virgili (España) y doctora en Ciencia Humanas por la Universidade Federal de Santa Catarina (Brasil). Post-doctorante en la Université Paris 8 Vincennes-Saint-Denis (Francia) y en la Universidade Federal de Santa Catarina. E-mail: martinhagofernanda@gmail.com

3 Doctora en Filosofía. Profesora del Departamento de Sociologia e Ciências Políticas y del Programa Interdisciplinar em Ciências Humanas de la Universidade Federal de Santa Catarina (Brasil). E-mail: sandracaponi@gmail.com
} 
Palabras claves: Cuba; Infancia; Criminalización; Reformatorios; Biopolítica.

Resumo: No século XIX, Cuba se transformava numa importante potência econômica, mesmo que continuasse dependendo da Espanha. Ao tempo que ocorriam uma série de transformações sociais, a criminalidade alterava o funcionamento da cidade. É assim que, como parte de uma estratégia biopolítica começam a introduzir-se mecanismos específicos de intervenções sobre aquela população de desamparados, de ambulantes, órfãos pobres e doentes mentais, colocados no imaginário social e no discurso político e intelectual como responsáveis de uma situação de insalubridade e periculosidade. Um setor alvo dessa estratégia biopolítica foi a infância pobre. Desde então, amparadas em um discurso caritativo, se criaram uma série de instituições reformatórias para crianças consideradas perigosas. Neste artigo, analisamos desde uma perspectiva foucaultiana o funcionamento de dois destes espaços: o Asilo San José, que funcionara até o fim da etapa colonial e a Escuela Correccional para varones, criada para substituir a anterior, mas com um desempenho similar.

Palavras-chave: Cuba; Infância; Criminalização; Reformatórios; Biopolítica.

Abstract In the nineteenth century, Cuba became an important economic power, although it continued to depend on Spain. At the same time as a series of social transformations were taking place, crime was increasing. Thus, as part of a biopolitical strategy, intervention mechanisms were introduced for this population of indigent, homeless, poor orphans and mentally ill, placed in the social imagination and political and intellectual discourse as responsible for a situation unhealthy and dangerous. A target sector of this strategy was poor children, for whom, through a charitable discourse, a number of reformatory institutions were created. In this article we analyze, from a foucaultian perspective, the functioning of two of these spaces: The San Jose Asylum, which had functioned until the end of the colonial period and the Correctional School for Boys, created to replace the previous one, but with a similar performance.

Keywords: Cuba; Childhood; Criminalization; Reformatories; Biopolitics.

DOI:10.11606/issn.1676-6288.prolam.2021.174187

Recebido em: 27/08/2020 Aprovado em: 30/07/2027 Publicado em: 01/07/2027

\section{Introducción}

En América Latina colonial los fundamentos socio-jurídicos de las estructuras punitivas de adultos y menores fueron los mismos que en 
Europa. A partir del siglo XIX las teorías criminológicas se ampararon en el carácter de cientificidad que les otorgaban el positivismo y las ideas de defensa social (MÉNDEZ, 1994). Además, había gran influencia del moralismo religioso, del modelo familiar burgués y del modelo capitalista de producción, que priorizan la laboriosidad como valor supremo y por tanto la acumulación de capital. Así, el desempleo y la vagancia, asociados a la pobreza, fueron cobrando más fuerza como antivalores y como comportamientos pasibles de punición, pero también de beneficencia.

Se creó así un modelo de gestión de la población desamparada, sustentado en un ideal de asistencia caritativa, realizada a través de una serie de instituciones como iglesias, casas de beneficencia, casas de socorro y orfanatos que combinaban la labor benéfica con la corrección física y moral; donde los menores comenzaron a ser un objeto prioritario (ANDRÉS-CANDELAS, 2016). Sabemos por Foucault (1999) que, por detrás del disfraz filantrópico se ejecutaba una función de vigilancia y control de las clases menos favorecidas, señaladas como "peligro social". Pero ese modelo de gestión no era exclusivo de Europa, sino que, como parte del dominio colonial fue importado a diferentes países latinoamericanos como Brasil, Colombia, Argentina, Uruguay, Chile y México.

En 1874, en Brasil en la ciudad de Río de Janeiro, a través del Decreto 5.532 se crearon diez escuelas para la instrucción primaria, una de ellas, la Casa de Asilo de los Niños desvalidos para albergar a menores abandonados de 12 años. Posteriormente, en 1883, por el Decreto 8.910 se permitió albergar a los menores pobres que no eran huérfanos, estableciéndose, además, la edad de 8 años para poder trabajar en la institución. La Casa Asilo siguió el modelo de las instituciones europeas, cuya idea de eliminación de la indigencia era por medio de la instrucción y del trabajo. En 1890, Deodoro da Fonseca, jefe del gobierno provisional, creó la asistencia a la infancia desvalida, por el Decreto 439, que define que el destino del Asilo de Niños Desvalidos era la recepción, el mantenimiento y la educación de menores desvalidos (ZANELLA, 2019). La noción de infancia en Brasil se asociaba a las clases sociales, siendo los niños pobres 
considerados como menores. "O menor é o pobre e o risco em criação, representa o criminoso e o doente em formação"4 (GONZAGA, 2018, p.185).

La investigación de Carrero (2012) presenta las tensiones entre los derechos de la infancia y los contextos de desigualdades y exclusión de la ciudad de Bogotá (Colombia). Los niños huérfanos menores de doce años, "los expósitos", tomados como transgresores del orden, del espacio escolar y familiar, fueron considerados como potencialmente anormales, como criminales en potencia. Los hijos de la pobreza, del vicio, de las relaciones prohibidas fueron considerados como niños ociosos, mendigos que representaban una amenaza social. Por eso, fueron recluidos en instituciones como el Hospicio o la Casa Refugio, la Quinta Camargo o el Asilo de la Infancia Desamparada, en la ciudad de Bogotá. Para esta población infantil se diseñaron prácticas de corrección o reforma de las costumbres supuestamente heredadas por su origen o por la condición social.

Otros países de América Latina también establecieron leyes, tribunales, instituciones dirigidas a la infancia marginalizada. En Argentina, en 1919, fue promulgada la Ley del Patronato o Azote, instaurando el menorismo, consolidando la idea de punición y creando un juzgado específico para menores. En 1939 se creó el primer Tribunal de Menores, en la provincia de Buenos Aires (STAGNO, 2008 apud ZANELLA, 2019).

En Uruguay, los casos de pérdida y restitución de la custodia, retirada de la guardia de menores, la corrección de niños infractores y la creación del Consejo de Protección de Menores quedaron definidas en el Código Civil, de acuerdo con la Ley 3.738 promulgada en 1911 (ZANELLA, 2019). Vale resaltar que, la primera casa para niños huérfanos fue creada en Montevideo (Uruguay) en 1818 y se llamó "La Inclusa". Esta institución presentaba una elevada tasa de mortalidad infantil debido a sus pésimas condiciones. "La Inclusa" pasó a llamarse Asilo de Expósitos y Huérfanos y,

\footnotetext{
${ }^{4}$ El menor es el pobre y el riesgo en creación, representa el criminal y el enfermo en formación (GONZAGA, 2018, p.185, traducción personal)
} 
posteriormente, en 1911, fue denominada "Asilo Dámaso Larrañaga" y después, en 1943 "Institución Larrañaga" (VÁZQUEZ, 2016).

Castillo Gallardo (2015) nos cuenta que, en Chile, muchos niños y niñas fueron esclavizados, transformados en siervos ilegítimos, colocados como vagos y delincuentes $\mathrm{y}$, en la modernidad, pasaron a ser trabajadores y trabajadoras explotados, para posteriormente ser escolarizados. El autor agrega que, actualmente, esta historia no es muy conocida por muchos niños, pues sus padres y abuelos ni siquiera se reconocen como parte de ella. En Chile, el primer Código Civil fue creado en 1855, definiendo que aquellos que cumplieran los 18 años como mayor de edad y aquellos que no, como menores. En 1928, por la Ley 4.447, se crearon los Juzgados de Menores y las Casas de Menores, con exámenes médicos y psicológicos para la observación y clasificación de los menores (ZANELLA, 2019).

Padilla (1998) presenta en su investigación las especificidades de las escuelas especiales en México, durante el siglo XIX. Esas instituciones buscaban nuevas formas de control social sobre los niños con características físicas, sociales, morales y económicas, las cuales necesitaban una educación especial. México tuvo su primer Tribunal de Menores en San Luis de Potosí y su Código Civil continuó utilizando el término menor en oposición al de mayor de edad. Los menores fueron incluidos en el sistema penal mexicano en 1929 con el Código Penal (ZANELLA, 2019).

Existen numerosos estudios que dan cuenta de la temática de la pobreza y la criminalización de la infancia en América Latina, no obstante, en esta investigación, nos dedicaremos a las particularidades de ese fenómeno en Cuba.

En el siglo XIX la Isla de Cuba se transformaba en una importante potencia económica, aun cuando continuase dependiendo económicamente de la metrópoli española (LÓPEZ, 2010). A la par del desarrollo económico de la isla colonizada, ocurrirían transformaciones sociales significativas, creando además espacios urbanos diversos. Al respecto, Apaolaza-Llorente (2018, p. 65) afirma que: “El poder no sólo debía 
mostrarse en grandes edificios con bellos diseños y materiales nobles, la ciudad es un ente orgánico que debía ser transformada en todos sus aspectos, tanto arquitectónicos y urbanísticos, como de comportamiento de sus habitantes".

La evolución de Cuba en la mayoría de los aspectos tendría su origen en las ideas de renovación que llegaban de Europa y a través de las que se pretendía hacía tiempo transformar a su capital, La Habana en una "ciudad moderna". A partir de ese momento, las autoridades coloniales, apoyadas por la burguesía cubana, establecerían una serie de medidas dirigidas a la modernización del país y la optimización de la vida cotidiana de sus habitantes. Esas disposiciones, instauradas bajo el ideal de la modernidad representaban una forma de biopolítica, toda vez que tenían como objeto de intervención el "funcionamiento de la ciudad", específicamente aquellos fenómenos como los "da natalidade, da morbidade, das incapacidades biológicas diversas, dos efeitos do meio...", que conforman aquel conjunto social Ilamado "população" (FOUCAULT, 2018, p. 206).

En la Cuba colonial, uno de los fenómenos que más alteraban el funcionamiento ideal de la ciudad y que provocaba altos índices de mortalidad era la criminalidad, la cual los sectores privilegiados asociaban a los grupos más pobres y marginados de la sociedad. De ese modo, comenzaron a introducirse mecanismos específicos de intervención sobre aquella población de desamparados, deambulantes, enfermos mentales y niños pobres, colocados en el imaginario social y en el discurso político e intelectual como responsables de una situación de insalubridad, pero también de peligrosidad (MORENO, 2017).

En este artículo pretendemos analizar los discursos sobre la criminalización de la infancia pobre en Cuba a finales del período colonial español y a comienzos de la etapa republicana, momentos en que comienza a estructurarse una estrategia biopolítica para el control y la normalización de esa población marginada. Dicha estrategia tendría como uno de sus espacios de ejecución a dos reformatorios para niños pobres 
ubicados en la capital del país: el Asilo San José, que funcionó hasta el final del siglo XIX y la Escuela Correccional para Varones, creada en los inicios del siglo XX.

Como punto de partida y fuente documental seleccionamos algunos textos (disposiciones legales, artículos de prensa, comunicaciones oficiales de eventos, etc.), producidos por figuras públicas relevantes de la época que versaran sobre la situación de la infancia pobre en Cuba, así como sobre las medidas interventoras del gobierno sobre ese asunto. Esas fuentes conforman los discursos sociológico, político, médico y jurídico sobre la infancia pobre considerada peligrosa en la Cuba de esos años, dentro de la cual autores como el destacado sociólogo y periodista José Antonio Saco (1797-1879), los gobernadores generales Miguel Tacón y Rosique (1834-1838) y Gerónimo Valdés (1784-1855), los médicos higienistas Manuel Delfín Zamora (1849-1921), Juan Bautista Valdés (18--? -19--?) y Matías Duque Perdomo (1869-1941), el jurista J. M. Peña (18--? -19--?) estuvieron entre sus principales representantes. Para llevar a cabo nuestro análisis nos apoyamos en los estudios de Michel Foucault (1980, 1999, 2003, 2008, 2018) y de Roberto Castel (2011) sobre biopolítica, dispositivos disciplinares y de normalización, discursos sobre riesgos y gobierno de la infancia. También en las contribuciones de autoras latinoamericanas que abordan tales temáticas como Sandra Caponi $(2004,2013)$ y Myriam Mitjavila (2002).

\section{Criminalidad y pobreza en los discursos intelectual y político cubano del siglo XIX}

En el caso de Cuba, la gestión de la población marginal y la infancia desamparada no fue esencialmente distinta a la de los otros países latinoamericanos. Así, quizás la imagen de niños y niñas ociosos y abandonados por las calles de la isla caribeña despertara entre las clases privilegiadas sentimientos contradictorios de compasión y rechazo, pero lo cierto es que tal situación provocó un movimiento creciente de demandas 
al gobierno para transformarla. Uno de los portavoces de ese "malestar social" sería el destacado sociólogo cubano José Antonio Saco, quien publicaría en 1830 un texto titulado La vagancia en Cuba, el cual, junto a Memoria sobre caminos, publicado en la misma época, le harían ganar a su autor dos medallas de oro en concursos de la Real Sociedad Patriótica de Cuba $^{5}$ (SACO, 1946).

Es probable que uno de los motivos que hiciera a "La vagancia en Cuba" un texto exitoso fuera que su autor trataba abiertamente la grave situación de desempleo en la cual se encontraban los cubanos en aquel momento. Pero esa cuestión no solo era abordada por los intelectuales, sino que esta ocupaba un lugar prioritario en el discurso político. En ese sentido, el gobernador de Cuba en aquel momento, Miguel Tacón y Rosique, afirmaba que, al momento de asumir su mandato, la isla se encontraba a en un cuadro de "desmoralización", describiéndolo de la siguiente manera:

un número crecido de asesinos, ladrones y rateros, circulaba por las
calles de la capital, matando, hiriendo y robando, no solo durante la
noche, sino en medio del día, y en las calles más centrales y
frecuentadas. (...). No bajaban quizás de doce mil las personas que
sin bienes ni ocupación honesta, se mantenían en la capital de las
casas públicas de juego, así de blancos como de individuos de color
libres y esclavos. Los vagos eran innumerables, y no pocos los que
encontraban medio de subsistencia en las estafas de todas
especies, y hasta en el mismo foro, ejerciendo unas veces las
funciones de testigos falsos, y otras las de alterar la paz de las
familias, atacando a ciudadanos pacíficos, que, por no verse
envueltos en los males inseparables de un pleito destructor,
compraban de los agresores la tranquilidad a un gran precio. Todos
estos elementos tenían entre sí una necesaria conexión, porque el
juego y la vagancia formaban los criminales de mayor categoría, y
todos estaban conjurados contra el orden público. (GOBIERNO Y
CAPITANíA GENERAL DE CUBA, 1838, p. 4).

Tanto para el intelectual José A. Saco como para el gobernador Miguel Tacón, la vagancia y la criminalidad tenían una relación bastante estrecha, de causa-efecto. No obstante, en el texto sobre la vagancia en Cuba, Saco va un poco más allá de una simple descripción de la situación

\footnotetext{
${ }^{5}$ La Real Sociedad Patriótica de Cuba fue una organización creada en 1792 con la finalidad de apoyar el desarrollo económico, educacional, cultural y social, reuniendo a los más importantes intelectuales cubanos de la época colonial.
} 
de inseguridad de Cuba, dedicándose a explicar las que él consideraba sus causas. Para Saco, resultaba evidente la existencia de una propensión en los seres humanos a obtener el sustento económico sin mucho esfuerzo y, para fundamentar su teoría coloca como mejor ejemplo de la vagancia a las mujeres pobres, a las que era común encontrar en las calles mendigando. Esas escenas le hacían afirmar que, el dinero que esas mujeres obtenían no tenía otro fin que el de mantener a sus maridos y sus hijos desempleados, a quienes llamaba despectivamente "holgazán" y "perdulario" (SACO, 1946, p. 58). Este argumento, además de mostrar la posición abiertamente misógina del autor, ya que deposita en las mujeres una culpabilidad por aquello que él considera un acto violatorio de las normas sociales, contribuye a reformar un discurso de rechazo y criminalización de la población pobre, colocada igualmente como responsable de no tener empleos. Pero el texto del sociólogo Saco no termina con su caracterización singular de la pobreza, sino que irá un poco más lejos y propondrá a las autoridades una serie de medidas para contrarrestarla. Entre esas medidas estaba aumentar los espacios de acogida para pobres, pero introduciendo un cambio radical en su concepción, los cuales pasarían de ser simples instituciones benéficas a centros especializados aislamiento de la población considerada peligrosa. De esa forma, según este nuevo esquema, esas instituciones "no solo servirán de asilo a la humanidad desvalida, sino de freno para contener los desórdenes que bajo el manto de la pobreza se cometen diariamente entre nosotros" (SACO, 1946, p. 58).

Otro elemento esencial en el proyecto de este intelectual sería la concepción del trabajo físico como transformador de las conductas consideradas peligrosas. Saco sugería que, además del encierro establecido, en las cárceles se aumentase el rigor disciplinar y se estableciera la obligatoriedad del trabajo forzado, debido a que la inactividad podría transformar a los presos en peores criminales. De esa forma, el trabajo físico no solo serviría como herramienta de punición, sino que se presentaba como una actividad de la cual se podría obtener algún 
beneficio económico para el país. El propio gobernador Miguel Tacón se referiría a esa supuesta ventaja:

\begin{abstract}
Jamás se había tratado de sacar partido de los confinados en el presidio de la Cabaña, ni de los sentenciados a obras públicas (...) Mandé entretanto construir en prolongación de la Nueva Cárcel, y dentro de la extensión de las 140 varas de fondo, dos cuarteles, capaz cada uno de ellos de recibir cómodamente 400 presidiarios. Dediqué el uno para los destinados a los trabajos de la ciudad, y el otro para los de extramuros (...) De esta manera, la sociedad a quien ofendieron los presidiarios saca de ellos el partido de que son susceptibles en las obras públicas de necesidad, utilidad y ornato, y tal vez se consigue que al fin de sus condenas, vuelvan aquellos desgraciados a ser miembros útiles, después de habituarse al trabajo, haber aprendido oficio y de haber sufrido su pena correccional (GOBIERNO Y CAPITANÍA GENERAL DE CUBA, 1838, p. 4).
\end{abstract}

Podemos comprender cómo el desempleo, tanto para el discurso intelectual como para el político, lejos de constituir una problemática a resolver por el gobierno colonial, se colocaba como una característica propia de la criminalidad. En ese mismo sentido, el trabajo no se tomaba como solución posible al desempleo, sino que, se aprovechaba como forma de castigo a las conductas reprobadas socialmente y como un modo de transformar en utilitarios a los sujetos marginados. Tanto el desempleo como la criminalidad constituían dos factores que influían directamente en la economía y en la mortalidad, alterando de esa forma el funcionamiento ideal de la ciudad y por tanto se tomaban como objetos de control de estrategias biopolíticas (FOUCAULT, 2018).

\title{
3. Niños pobres, ¿Delincuentes?
}

Continuando con el intelectual cubano José A. Saco (1945), encontramos en su texto una marcada referencia a los niños pobres, apuntados como un factor decisivo en la situación de criminalidad y desempleo por la que atravesaba Cuba en aquellos momentos. Aunque Saco hacía un llamado a las autoridades para que dirigieran la mirada a la situación deplorable de esos niños, en realidad su discurso mostraba otra intención, pues lejos de responder a un acto humanitario, exigía que se 
tomaran medidas coercitivas un poco más radicales contra los pobres y marginados, incluidos los menores de edad. Además, en su propuesta, los niños pobres tendrían un lugar prioritario como objeto de las acciones correctivas, basado en la idea de que la severidad frente a las conductas marginales precoces serviría para prevenir la futura criminalidad. En ese sentido, afirma Mitjavila (2002), la creencia en la posibilidad de un riesgo futuro sirve de fundamento para la aplicación de cualquier medida que parezca eficaz para enfrentarlo.

Podemos preguntarnos entonces, ¿por qué la infancia era objeto de interés especial en el discurso de los académicos cubanos de los cuales José A. Saco formaba parte? La conducta de los niños, en la medida que presentase ciertas señales de desvío de la norma, se transformaba en un indicador de riesgo, y en el caso de la infancia pobre y marginada se asociaba automáticamente a la posibilidad de un futuro desempleado y criminal. Esa situación se presentaba como una especie de amenaza externa para las clases privilegiadas, las que, obviamente se desmarcaban de los grupos sociales menos favorecidos. En ese sentido, Robert Castel afirma que "la cuestión del vagabundeo fue la gran preocupación social" (CASTEL, 2011, p. 18) en las sociedades preindustriales europeas, pero como podemos ver también en las colonias americanas como Cuba. Según Castel, la existencia de esos grupos de desempleados "movilizó una cantidad extraordinaria de medidas de carácter dominantemente represivo para intentar erradicar -por otra parte, en vano- esa amenaza de subversión interna y de inseguridad cotidiana que supuestamente representaban los vagabundos".

$Y$ en el caso de la infancia pobre las cosas no debían ser muy diferentes. En Cuba la figura del "niño vagabundo", la supuesta amenaza que representaba aparecía en dos dimensiones, la económica y la moral. En la dimensión económica, el niño vagabundo formaba parte de ese grupo que Castel caracteriza como "riesgo social", a partir de su posición como "incapaz de gobernar su existencia a partir de sus propios recursos" y que por tanto dependería de la asistencia social para sobrevivir (CASTEL, 
2011, p. 35). Obviamente la inexistencia de recursos les venía a esos niños a partir del desamparo económico en que también se hallaban los adultos a cargo de ellos. En cuanto a la dimensión moral y esta sería la más importante en cuanto a la estrategia de prevención, el niño, en plena formación de su subjetividad, es tomado como alguien que podría ser moldeado en función de determinados intereses de la sociedad. Al respecto Foucault (1980) afirma que la infancia se convierte, a partir del siglo XVIII en un objeto privilegiado de las estrategias de control del gobierno, toda vez que cualquier inversión en el desarrollo del niño, un manejo "adecuado" de esta etapa vital podría garantizar adultos útiles socialmente, y también económicamente productivos. Por consiguiente, lo que los discursos académicos y políticos proponían era que el control y la normalización de la infancia pobre además de garantizar su utilidad económica, evitaría que se presentasen en un futuro conductas desviadas o criminales. De ahí que Saco celebraría como un acierto del gobierno la existencia, dentro de la Casa de Beneficencia de La Habana ${ }^{6}$, de un departamento dedicado exclusivamente a internar niños y niñas huérfanos y desamparados, con la finalidad de "preservarlos" de ciertos "males" como el "ocio" o "la perdición" (SACO, 1945, p. 59).

Siendo José A. Saco un intelectual reconocido en la época, no debe extrañar que sus ideas tuvieran una buena recepción dentro del gobierno y las clases privilegiadas. De acuerdo con el historiador Reinier Borrego Moreno (2017), la construcción de la Real Cárcel de La Habana en 1834 (a sólo tres años de publicado el libro "La vagancia en Cuba"), demostró que se venía estructurando una nueva estrategia de represión a la criminalidad, amparada en el discurso sobre la peligrosidad de la población marginada. Según este autor, otra medida de importancia adoptada en ese sentido fue la creación de un dispositivo de control singular, desde donde, la prefectura de La Habana, junto a la policía y algunas instituciones caritativas,

\footnotetext{
6 Institución benéfica creada en la Ciudad de La Habana con el fin de acoger a niños y niñas abandonados, aunque también fueron recluidas allí mujeres diagnosticadas como dementes. Esta institución se mantendría en funcionamiento entre los años 1794 y 1961.
} 
cumplían con la misión de retirar sistemáticamente a los desamparados, a los vagos y a los alcohólicos que deambulaban por las calles de la ciudad. Pero la única idea de José Antonio Saco que tuvo aceptación no fue la de habilitar espacios de reclusión para pobres, también la cuestión del trabajo forzado como tecnología disciplinar sería usada, incluso en los niños considerados peligrosos, como se verá posteriormente.

En consecuencia, algunos años después, en 1842, queda establecido por ley, específicamente en el artículo 36 del Bando de Gobernación y Policía de la Isla de Cuba emitido por el gobernador Gerónimo Valdés, un mandato de prisión para niños y niñas deambulantes menores de 12 años y que no tuvieran amparo filial. Esa nueva norma no sería de difícil aplicación para las autoridades y dejaba delimitado a qué público específico se dirigía pues eran precisamente los niños pobres los únicos deambulantes, lo que vino a reforzar el ya ganado estigma de peligrosidad. Según esa ley, los menores detenidos deberían permanecer encerrados en las cárceles de la ciudad por un periodo de 48 horas y si no eran reclamados por ningún adulto, podrían ser enviados automáticamente a la Casa de Beneficencia. Ya en el caso de los niños y niñas con edades entre 12 y 17 años, en vez de ir a la Casa de Beneficencia, les esperaba el trabajo en la agricultura o en oficios similares, que requerían un esfuerzo físico superior a lo que permitía su edad (VALDÉS, 1842).

\section{El "mataperro", ese incorregible}

Dentro del grupo de niños desamparados había algunos que llamaban particularmente la atención, tanto de los pobladores como de las autoridades, por ser considerados extremadamente peligrosos. Se trataba de los "mataperros". Según relata el escritor José Joaquín Hernández (1958), el mataperro era un niño de entre 8 y 16 años, la mayoría de las veces de piel negra o mestiza, el cual no había recibido ningún tipo de educación, ni en la escuela ni en la familia y se caracterizaban por un rechazo abierto a toda institución escolar, pero también por una posición desafiante frente a 
toda norma social. El mataperro, según se afirmaba, "siempre anda sucio y mal vestido y a veces descalzo y sin sombrero" y le gustaba además andar solo por las calles, desafiando cualquier límite o norma social (HERNÁNDEZ, 1958, p.162). Había una diferencia entre este y los otros niños pobres ya que, el niño pobre siempre podía contar con la ayuda de algún pariente que lo representase frente a cualquier problema, incluso que se preocupase por su educación y su desarrollo, pero eso, desgraciadamente no ocurría con el mataperro, quien encarnaba al verdadero desamparado.

Además de esa diferencia, el mataperro asumía una postura de desafío constante frente a cualquier autoridad. En ese sentido, Hernández (1958) afirmaba que, cuando el mataperro era detenido por la policía, si no conseguía escapar -cosa bastante improbable-, era bien capaz de convencer a su captor de su inocencia. Este autor describe la escena de la captura de un mataperro de la siguiente forma: cuando es sorprendido "se disculpa a las mil maravillas y queda como inocente", volviendo seguidamente a cometer una de sus travesuras preferidas, la de perseguir cualquier animal que se le atravesase en su camino, pero sobre todo perros, hacia los que sentía predilección por golpearlos. Es justamente de ahí que le viene el mote de "mataperros". Agrega Hernández (1958) que los golpes que a veces recibía el mataperro por parte de los dueños de los animales para nada le afectaban, pues la mayoría de las veces conseguía esquivarlos con maestría singular. Pero lo que más incomodaba tanto a los pobladores como a las autoridades era la actitud desafiante del mataperros, lo que lo situaba en una categoría de peligrosidad diferente, la de "incorregible".

Es justamente ese individuo incorregible del cual hablaba Foucault (2018) en su curso Os Anormais, el cual se ubicaba en ese espacio conflictivo donde se entrelazan figuras de autoridad como la familia, la escuela, la iglesia, el barrio, la calle, la policía, etc. Lo que resultaba perturbador para la sociedad en el caso de la infancia "peligrosa" y del mataperro era no solo la ausencia de una estructura familiar acogedora y de un vínculo con otras instituciones normalizadoras, como la escuela o la 
iglesia, sino que estos niños parecían cargar con el estigma de un destino nefasto y de la inutilidad social. Foucault, en ese mismo curso dirá que ese individuo se presenta ante la sociedad como "incorregible", debido a que "fracassaram todas as técnicas, todos os procedimentos, todos os investimentos familiares e corriqueiros de educação, pelos quais se pode ter intentado corrigi-lo"7. Por tanto, continúa Foucault, el ser incorregible será la justificación para "uma nova tecnologia da reeducação, da sobrecorreção"8 (FOUCAULT, 2018, p. 50).

De modo que, la infancia incorregible comenzaba a ser colocada en una condición diferente de aquellas comúnmente atendidas por las instituciones benéficas. Los niños y niñas acogidas por la beneficencia, probablemente se mostraban más dóciles frente a las autoridades y la sociedad, pero los "menores delincuentes" (MORENO, 2015), considerados peligrosos, no gozarían de tal "privilegio". Para ellos será implementado un dispositivo más severo que, si bien no era la cárcel común, tampoco sería un centro tradicional de caridad.

\section{El asilo san josé}

En 1857 se funda el asilo San José, destinado a la corrección de los menores vagos y delincuentes en la capital de Cuba. El asilo se situaba estratégicamente en una zona periférica de la ciudad, conocida popularmente como "extramuros" y reservada a las poblaciones más pobres de la capital. Teniendo como vecinos próximos el cementerio principal de la ciudad, el leprosorio, el asilo para dementes y una cantera a donde eran llevados los prisioneros para realizar trabajos forzados, era evidente que la intención de las autoridades era mantener separados a estos niños del resto de los habitantes, como forma de prevenir el supuesto riesgo que representaban. Además, seguramente el paisaje de esta zona

\footnotetext{
7 "Fracasaron todas las técnicas, todos los procedimientos, todas las inversiones familiares y comunes de educación, a través de las cuales se puede haber intentado corregirlo" (FOUCAULT, 2018, p.50, traducción personal).

8 "Una nueva tecnología de la reeducación, de la sobrecorrección" (FOUCAULT, 2018, p.50, traducción personal)
} 
apartada, enriquecida con la imagen de leprosos, dementes y prisioneros trabajando duramente bajo pésimas condiciones, serviría como un espejo donde el niño delincuente debía mirar su futuro si no se convertía en sujeto dócil. Enrique (2010) describe esa parte de la ciudad extramuros de la siguiente forma:

en aquella época, esta era una zona deprimida y mustia en extramuros, en principio muy alejada del centro, lejos de las miradas de los viajeros, territorio relegado al encuentro con la enfermedad, la locura, la pobreza y la muerte, tal y como delatan los edificios e infraestructuras que se levantaron en esos términos ( $p$. 196).

Es así cómo, el asilo San José, institución alternativa a la Casa de Beneficencia y a las cárceles de adultos marcaría el nacimiento de una nueva tecnología biopolítica en la Cuba decimonónica, de esta vez dirigida a los "menores delincuentes". Se trataba de intervenir a un nivel más sofisticado sobre aquella población de niños pobres considerados una amenaza a un funcionamiento equilibrado de la ciudad. A partir de ese momento, y durante toda la etapa colonial, serían enviados indistintamente para esa especie de cárcel infantil a los menores deambulantes, los vagos y aquellos condenados judicialmente. Obviamente ninguno de esos niños pertenecía a las clases privilegiadas, lo que demuestra que las formas de punición de las conductas desviadas eran claramente selectivas, reservándose la mayor severidad a los menos favorecidos económica y socialmente.

Según afirma Moreno (2017), en la década de 1870, a causa de la insurgencia anticolonial conocida como la Guerra de los Diez Años ${ }^{9}$, el asilo San José sería utilizado como cárcel para adultos, específicamente para esclavos cimarrones capturados y para emancipados que cometieran algún tipo de delito, sobre todo relacionados con la insurrección. Tal situación contribuía a reforzar la configuración de cárcel que tenía este asilo, más que de institución benéfica o pedagógica. Además de ello, no existía una división clara entre la población carcelaria y la infantil, lo que

\footnotetext{
${ }^{9}$ La Guerra de los Diez Años comenzó en octubre de 1868 y terminó en febrero de 1878. Sería la primera de tres guerras de independencia llevada a cabo por los cubanos contra el dominio colonial español.
} 
vendría a complicar más la situación de los niños, sobre todo porque se les reprimía por igual a cada uno de estos grupos. No obstante, afirma este autor, a partir de 1874, el nuevo alcalde corregidor de La Habana, llamado Julián Zulueta, establecería un nuevo régimen disciplinar dentro asilo, lo que en la práctica se traduciría en el aumento de los abusos ya cometidos por los guardias tanto sobre los niños como sobre los presos. El nuevo reglamento consistía en un régimen estricto de control, con vigilancia permanente tanto de los horarios de los internos, además de la introducción del trabajo forzado, con el fin de garantizar la corrección de las conductas, sobre todo de los menores delincuentes.

El uso correccional del trabajo hacía tiempo era una práctica común en las cárceles de la ciudad y como ya habíamos visto, era defendido en los discursos políticos e intelectuales de la época. Según Martínez (2012), en el sistema carcelario cubano tanto los presos por delitos comunes como los vagos, fueron utilizados como mano de obra barata en diferentes labores y, sobre todo, en las construcciones de fortificaciones militares. Así, muchos fueron empleados como "constructores, carpinteros, herreros, chapeadores, piqueros, canteros" a cambio solo de alguna ropa, calzado y raciones de comida (p. 132). Desde esta concepción, la corrección ocurría a través del aprendizaje obligatorio de diferentes oficios como la zapatería, la talabartería y la tabaquería. Ese principio correccional, en sus dos dimensiones, disciplinar y laboral venía siendo aplicado hacía tiempo en las llamadas Casas Correccionales ${ }^{10}$ para menores en la propia metrópoli española (SIERRA, 1999, p. 95), por lo que no sería muy difícil que fuera aplicado en el correccional cubano.

En efecto, el trabajo de tipo mecánico mediante el entrenamiento del cuerpo en labores que requerían de repetición monótona respondía a una concepción de la disciplina como forma eficaz de dominación, que, según Foucault (2003) venía desarrollándose en el transcurso de los siglos XVII y XVIII en Europa. Para este teórico francés la disciplina, aplicada mediante el

\footnotetext{
${ }^{10}$ En el siglo XIX fueron creadas en España dos instituciones de ese tipo, la Casa de Corrección de Barcelona (1836) y la Casa de Corrección de Madrid (1840) (SIERRA, 1999).
} 
ejercicio físico se basaba en una serie de "métodos que permiten o controle minucioso das operações do corpo, que realizam a sujeição constante de suas forças e thes impõem uma relação de docilidade-utilidade"l (FOUCAULT, 2003, p. 118). Así, se aspiraba a que los oficios que esos niños "menores delincuentes" aprendían obligatoriamente, los transformarían en sujetos dóciles, pero también económicamente útiles. En ese sentido, subraya Foucault (2003, p. 119): "a disciplina aumenta as forças do corpo (em termos económicos e de utilidade) e diminui essas mesmas forças (em termos políticos e de obediência)"12.

\section{La corrección de la "niñez delincuente" en la etapa republicana}

En los inicios del siglo XX terminaba el período colonial en Cuba y comenzaba un nuevo ciclo que implicó cambios tanto económicos, políticos y sociales. Al tiempo que Cuba se tornaba independiente de España se produjo la primera intervención oficial norteamericana en el país, marcando el inicio del período republicano (1902-1959), como se conoce en la historiografía cubana (GARCÍA, 2000). Ese fue el período de mayor influencia estadounidense en todos los ámbitos de la sociedad cubana, interrumpido solamente en la década de 1960 con la llegada al poder de Fidel Castro y el comienzo de la revolución cubana. Es así como, en la República y después de la última guerra de independencia (1895-1898), la nación quedó sumergida en una importante crisis económica, provocando que muchos habitantes quedaran en una situación de miseria absoluta. Unido a ello, crecieron cada vez más las diferencias de clases, la discriminación racial y el rechazo a la población pobre. Como consecuencia, aumentaría la criminalidad, pero también la mendicidad, sobre todo entre niños y jóvenes, muchos de ellos huérfanos a causa de la guerra reciente (MORENO, 2015).

\footnotetext{
"Métodos que permiten el control minucioso de las operaciones del cuerpo, que realizan la sujeción constante de sus fuerzas y les imponen una relación de docilidad-utilidad" (FOUCAULT, 2003, p. 118, traducción personal).

12 "La disciplina aumenta las fuerzas del cuerpo (en términos económicos y de utilidad) y disminuye esas mismas fuerzas (en términos políticos y de obediencia)" (FOUCAULT, 2003, p. 119, traducción personal).
} 
Para resolver los problemas sociales, el nuevo estado republicano intentaría realizar una serie de reformas en dos ámbitos medulares: la salud y la educación. Para ello, se apoyó en el modelo norteamericano. En el caso de la salud, se intentaría fortalecer las políticas sanitarias y las medidas de higiene pública, ya que, junto a la situación de miseria de la población había crecido el número de las enfermedades contagiosas y las epidemias. A partir de ahí, se crearon algunas instituciones dirigidas al control sanitario y epidemiológico, las que intervendrían directamente sobre asuntos como la natalidad y la mortalidad de la población, buscando modificar la situación precaria de los hospitales, los asilos, las escuelas, los talleres, pero también de los cementerios y los mataderos (CHAPLE, 2014). Según lo planteado por Foucault (2018), podemos comprender cómo esas instituciones recién creadas suponían la continuidad de una estrategia biopolítica iniciada en el período colonial, donde no solo se trataba del dominio de las poblaciones, sino que implicaba formas de ejercicio del poder particulares que irán actualizándose en los diferentes momentos históricos (CAPONI, 2013). De esta vez, con el gobierno republicano y la influencia directa de los Estados Unidos, la estrategia biopolítica se tornaría más sofisticada.

Ya en el caso de la educación ocurriría de modo similar al de la salud. Como primera medida, el gobierno cubano priorizaría la construcción de varias escuelas públicas, introduciendo en ellas el patrón cultural norteamericano, lo que implicaba el estudio obligatorio del idioma inglés y de los valores cívico-morales de aquella sociedad (RAMÍREZ, 2009). En el punto de articulación entre las acciones sanitarias y las educativas del gobierno, encontraremos a las instituciones benéficas, surgidas en la etapa colonial, pero adquiriendo cada vez más importancia en este nuevo período. Esos espacios de acogida de la población pobre cumplirán una doble función en la política higienista del Estado: la primera, continuar sirviendo como depósito de niños y niñas desamparados que deambulaban por la ciudad y, la segunda, funcionar como centros de reeducación y corrección de conductas desviadas de las normas sociales. 
De tal manera, Moreno (2015) afirma que, en los comienzos del siglo XX se percibe un cambio en las formas de atención y control de la pobreza, traducido en una demanda cada vez más fuerte al Estado para que interviniese sobre ese fenómeno. Uno de los objetivos de esas intervenciones continuaba siendo la población de niños y niñas pobres desamparados, clasificados en muchos casos como delincuentes. Es importante destacar que, en la época colonial el control sobre la población de niños "peligrosos" era más simple, pues la responsabilidad por su evaluación recaía exclusivamente en jueces o policías, y en dependencia del nivel de riesgo determinado se les enviaba a la Casa de Beneficencia o al asilo San José. ${ }^{13}$ Desde el punto de vista del sistema jurídico, que funcionaba desde la lógica infracción-punición, la categoría de menor delincuente dependía de dos elementos clasificatorios. El primero era ser un "vago de oficio", lo que significaba andar regularmente por las calles, deambulando sin ninguna ocupación. Como habíamos visto anteriormente, la vagancia era un fenómeno bastante común desde la etapa colonial y los niños eran particularmente vulnerables a ello por causa de la pobreza, el abandono y la orfandad. Esa situación los empujaba a deambular por las calles en la búsqueda de algún tipo de sustento alimenticio, pero también a pedir limosnas en vez de asistir a alguna escuela o poder quedarse en la seguridad de un hogar. Pero también el dispositivo judicial contaba con otro recurso clasificatorio: la educación moral, desde el cual se evaluaba que esta no fuera "tan atrasada que exista el peligro de que dicho menor se convierta un día en criminal" (PEÑA, 1904, p. 220). Evidentemente, la prioridad no era el nivel educacional del niño, sino el seguimiento de determinados patrones morales impuestos sobre todo por la iglesia y las clases privilegiadas. Pero en esta nueva etapa, además de la existencia del aparato jurídico, se introducen los discursos pedagógicos y médicos sobre la infancia marginal y peligrosa, lo que vendría a complejizar la estrategia biopolítica, de esta vez apoyados en las

\footnotetext{
13 Históricamente la beneficencia en Cuba se organizaba a partir de las siguientes entidades: "Casas de expósitos y maternidad, asilos para mendigos, hospitales y manicomios" (MORENO, 2015, p. 57).
} 
ideas higienistas. Desde esa perspectiva, tanto en la pedagogía como en la medicina, el cuerpo del niño se tornaría el principal objeto de intervención, procurando así formar "una ciudadanía apta intelectual y físicamente" (NUÑEZ, 2012, p. 98).

Para alcanzar una mejor organización en ese sentido, comenzaron a realizarse en el país una serie de encuentros anuales bajo el nombre de Conferencia Nacional de Beneficencia y Corrección de la Isla de Cuba. Este evento, se realizaba en provincias diferentes del país y reunía a destacados intelectuales y profesionales cubanos, así como a invitados norteamericanos, de diferentes campos del saber, como la medicina, el derecho, la antropología y la pedagogía (FERNÁNDEZ, 1998). Dichos asistentes fungían como representantes de las instituciones privadas y estatales encargadas de las acciones de caridad en los respectivos países. En cada uno de estos encuentros, los debates giraban en torno de la labor benéfica a los desvalidos y las medidas de corrección de la criminalidad realizados bajo la consigna de la atención "del débil, desamparado, enfermo o moralmente desviado" (CONFERENCIAS DE BENEFICENCIA Y CORRECCIÓN, 1904, p.11). Al respecto, afirma Rodríguez (2018) que, si bien estas conferencias no consiguieron solucionar todos los problemas que preocupaban a la sociedad en aquella época, su intervención fue decisiva al otorgar un carácter científico a las explicaciones sobre el fenómeno de la marginalidad y a las propuestas de soluciones.

\section{La escuela correccional para varones de Cuba}

Finalmente, para la corrección de la infancia "peligrosa" se crearían dos instituciones: la Escuela Correccional para párvulas de Cuba y la Escuela Correccional para varones de Cuba, que no era otra que una versión actualizada del antiguo asilo San José. En la Escuela para párvulas, se recluía a niñas y adolescentes desamparadas acusadas de cometer diferentes delitos, pero sobre todo de dedicarse a la prostitución. El médico 
higienista cubano Matías Duque, en su libro La prostitución, sus causas, sus males, su higiene (1914) describía a esa escuela como:

\begin{abstract}
un asilo donde debían ser recluidas, para su reforma moral, las menores delincuentes, pero la Administración cubana (...) entendió por delincuentes también a las menores prostitutas, y así como confundió estos términos, confundió en el mismo asilo a aquellas y a las niñas prostitutas. (DUQUE, 1914, p. 149)
\end{abstract}

Por otro lado, la Escuela para varones seguía funcionando tal cual lo hacía en la época colonial, como centro de internamiento para niños pobres de entre 10 y 16 años, condenados por la comisión de delitos o apresados por la policía por considerarlos un riesgo social. Dentro de la institución funcionaba un aparato de reformación sobre dos ejes fundamentales: la modificación de las conductas mediante un sistema de premios y castigos, y la sustitución de las actividades libres por el trabajo físico. En el primer eje, el niño recibía algún premio siempre que su conducta fuera la esperada por sus encargados, pero si su comportamiento les parecía inadecuado, lo que recibían era el castigo. Desde ese esquema positivista, orientado desde la psicología conductual norteamericana, se buscaba conseguir la "regeneración moral" de los niños delincuentes internados allí (PEÑA, 1904, p. 221). El premio por la conducta esperada consistía en una reducción de la sanción hasta dos años, lo cual indicaba además que ya el niño se encontraba "reformado" y, por tanto, listo para una libertad condicional. El castigo, por su parte, podía ser el traslado o el retorno del niño a la cárcel común, bajo la premisa de que ya no había forma posible de reformar su comportamiento, ocurriendo sobre todo en los casos de los menores señalados como líderes negativos.

Así, el trabajo del reformatorio se consideraba exitoso cuando el menor delincuente había adquirido los "hábitos de trabajo, obediencia y buena conducta", o sea, que volviese a un estado ideal de normalidad (PEÑA, 1904, p. 221). En ese sentido, Foucault (2008) apuntaba a ese ideal de normalidad como esencial a los dispositivos disciplinares. Es decir, el objetivo de los mecanismos normalizadores va a ser lograr que los 
individuos ingresen en un sistema de entrenamiento gradual y control interrupto, para transformarlos en modelos de sujetos dóciles y adaptables a ciertos patrones sociales (FOUCAULT, 2008). La docilidad entraba en sintonía con un nuevo modelo de ciudadano pretendido por las autoridades cubanas. Según afirma Núñez (2012), después de conquistada la independencia de España y en el comienzo de la República cubana, se esperaba poder formar un nuevo tipo de ciudadano, gobernable por el Estado y comprometido ya no con la cuestión emancipadora, sino con la construcción de una sociedad republicana. Por tanto, serían esos niños reformados, convertidos en ciudadanos y trabajadores dóciles los que se esperaba encontrar luego de su paso por el reformatorio.

Es por esa razón por la que se priorizaba el trabajo físico en la institución, siendo este el segundo eje del aparato de normalización. Al respecto, el pediatra e higienista cubano Manuel Delfín Zamora afirmaba que "Cuba demanda hombres que labren la tierra (...); cubanos que no se marchiten en las sombras de nuestras poblaciones, envilecidas por el vicio y por los crímenes" (ZAMORA, 1904, p.47). El también médico higienista Juan B. Valdés, definía el objetivo de los reformatorios de menores delincuentes de la siguiente forma: "de niños débiles tratar de conseguir hombres sanos y robustos, de niños ignorantes, instruidos y educados; de niños holgazanes, activos y laboriosos, de niños de mal comportamiento y malas costumbres, sumisos y morigerados" (VALDÉS, 1904, p. 39).

Así, como habíamos visto anteriormente, si desde esta concepción el entrenamiento del cuerpo produciría docilidad y a la vez utilidad (FOUCAULT, 2003) la actividad principal a la que serían sometidos los niños del correccional iba a ser el trabajo físico. Esos niños debían trabajar directamente en labores agrícolas no sólo como aprendizaje del oficio, sino como una forma de autoabastecerse de alimentos al propio correccional y así, atenuar los gastos del Estado ${ }^{14}$; también podían aprender la carpintería, la herrería, la zapatería, la albañilería, la sastrería, la pintura de inmuebles

\footnotetext{
${ }^{14}$ La producción agrícola de los niños del reformatorio se usaba también para la alimentación de las niñas recluidas en la Escuela Correccional para Párvulas de Cuba (MORENO, 2015).
} 
(MORENO, 2015). Ese entrenamiento sistemático y automático de los cuerpos, además de la función utilitarista demostraba su intención normalizadora.

Por otra parte, el aprendizaje de esos oficios y el trabajo físico como forma de educación de la infancia se amparaba en un discurso asistencialista, que partiendo de la suposición de que, con esos saberes, el futuro laboral de esos niños estaría garantizado y, por tanto, no serían una carga para el Estado y la sociedad. De ese modo, se suponía que la supuesta peligrosidad de los menores desamparados dejaría de ser un problema en el futuro, toda vez que, al tener un oficio, no tendrían necesidad de dedicarse a la vagancia o a la comisión de delitos. Al respecto, Sandra Caponi sostiene que "essas estratégias mudas e coercivas que se exercem sobre os corpos (pensemos na medicalização e hospitalização dos 'loucos' ou dependentes) insistem e apresentar-se como formas compassivas e piedosas de socorro e assistência"15 (CAPONI, 2004, p.41). Es así como, a través del sistema de premios y castigos por conductas, y con el trabajo físico como fórmulas correctivas en la infancia, se mantendría funcionando por varios años la Escuela Correccional para varones de Cuba. No obstante, la efectividad de ese método resultaba dudosa, ya que, según plantea Moreno (2015), el destino de la mayoría de esos niños recluidos allí acababa siendo la cárcel, una vez que cumplían la mayoría de edad penal. Unido a ello, se registraron con bastante frecuencia fallecimientos tanto por enfermedades como por situaciones de violencia extrema. Varios años más tarde, en 1936, aparecería una nueva ley, el Código de Defensa Social, la cual modificaría algunas de las normas referentes al tratamiento punitivo de los menores. Entre las modificaciones se encontraba el aumento de la edad penal para doce años y la introducción de un atenuante para las edades entre doce y dieciocho años. Además, se incorporaron medidas tutelares como la prisión domiciliar, la hospitalaria y la tutoría escolar

\footnotetext{
15 "Esas estrategias mudas y coercitivas que se ejercen sobre los cuerpos (pensemos en la medicalización y hospitalización de los 'locos' o dependientes) insisten y se presentan como formas compasivas y piadosas de socorro y asistencia" (CAPONI, 2004, p.41, traducción personal).
} 
(ORTIZ, 2011). Sin embargo, lo más significativo de esa ley era que ordenaba la eliminación del modelo de "escuela correccional", disponiendo el traslado de los menores reclusos para una nueva institución, con la promesa de garantizar reglas más flexibles y mejores condiciones de vida. A pesar de ese cambio, todavía hoy existen en Cuba instituciones que, bajo otros nombres, continúan con la misión de reformar a la infancia peligrosa, mediante el uso de métodos similares.

\section{Consideraciones finales}

El desempleo, asociado a los altos niveles de criminalidad que existían en Cuba durante el siglo XIX contribuyeron a la consolidación de un discurso de riesgo sobre la población pobre y marginada. Así, esa población se transformó en el objeto priorizado de una estrategia biopolítica del gobierno colonial español, que procuraba mantener el funcionamiento del país y la optimización de la vida de los habitantes. Dicha estrategia buscaba, además, colocar a Cuba dentro del estándar europeo, influenciado sobre todo por el movimiento de la llustración. En ese primer momento, correspondiente a la etapa colonial, las clases privilegiadas, junto al discurso intelectual y político, colocaban a la pobreza como telón de fondo de la peligrosidad social. Desde esos lugares se establecieron demandas concretas al gobierno para la ejecución de medidas preventivas y punitivas, las que supuestamente vendrían a resolver la cuestión de la criminalidad y traer un equilibrio social. A partir de ahí se introdujeron una serie de mecanismos para intervenir sobre esa población identificada como la causa principal de los problemas sanitarios y de seguridad en el país. La infancia pobre sería, dentro de los desamparados, uno de los sectores sobre los cuales se intervendría más.

Es así como el discurso sobre la prevención de los riesgos serviría de base para la aplicación de acciones correctivas sobre niños y niñas clasificados como incorregibles, siendo una de las más importantes la creación de asilos y escuelas reformatorios. En este trabajo, por motivo de 
espacio, pero también por las diferencias notables entre las instituciones, nos dedicamos exclusivamente al análisis de los establecimientos para niños, especialmente el asilo San José y la Escuela Correccional para Varones. El asilo San José, sería localizado de manera expresa en la periferia de la ciudad, como forma de establecer una división entre esa población infantil considerada peligrosa y el resto de los habitantes de la ciudad. Con un funcionamiento algo rústico comparado con instituciones posteriores, la función principal de este asilo fue la reclusión de los niños llamados delincuentes, utilizando tanto castigos corporales como el trabajo físico sobre un estricto régimen disciplinar semejante a la cárcel para adultos. No obstante, aunque predominasen la internación y el castigo como medios de corrección de conductas, la cuestión del trabajo físico aparece como otra fórmula aplicable. La técnica de tornar a la peligrosidad en algo útil a través del trabajo forzado va a ser el elemento que se mantuvo como una constante cuando el asilo pasó a ser una escuela correccional. En ese cambio de nomenclatura, de "asilo" a "correccional" para menores, encontramos el indicador de una sofisticación del discurso sobre el riesgo, que pasó de apoyarse en una simple cuestión de punición, para usar, además de eso, los saberes médicos y pedagógicos, orientados desde el higienismo.

Posteriormente, con el advenimiento de la República y la intervención norteamericana en Cuba, el modelo de corrección de la infancia peligrosa se tornaría más complejo y especializado. La aparición de nuevos saberes, sobre todo los de la medicina higienista, tuvieron una enorme influencia en esa transformación. La nueva clasificación de escuela correccional ilustra muy bien que se trataba de una nueva forma de gobierno de esos niños "peligrosos", desmarcándose del modelo asilar, para mostrarse un poco más humanitario. De cualquier forma, esa nueva estrategia no abandonaba el matiz biopolítico de la gestión de la infancia marginada considerada de riesgo, pues la labor de la escuela correccional continuaba existiendo sobre el principio de transformar la pobreza 
considerada peligrosa en una fuerza de trabajo utilitaria. Después de la desaparición de la Escuela Correccional para Varones en 1936, aparecieron otras formas de gestión de esa población y surge la cuestión de saber si esos nuevos esquemas responderían a nuevas formas de biopolítica.

\section{Agradecimientos}

Esta investigación fue realizada con el apoyo de CAPES a través del Programa de Estudiantes Convenio de Posgraduación (PEC-PG).

\section{Referencias}

ANDRÉS-CANDELAS, Mario. La construcción socio-histórica de la "infancia peligrosa" en España. Revista Latinoamericana de Ciencias Sociales, Niñez y Juventud, v. 4, n. 1, p. 95-106, 2016. DOI 10.11600/1692715x.1415220615. Disponible en: https://dialnet.unirioja.es/servlet/articulo?codigo=5382020. Acceso en: 21 dic. 2020.

APAOLAZA-LLORENTE, D. La Habana ilustrada del siglo XVIII. Sus transformaciones urbanas a través de la mirada de los bandos de buen gobierno. "Cambiando la imagen de poder". Iberoamérica Social: Revista-red de estudios sociales, n. ESPECIAL, p. 63-80, 20 feb. 2018.

CAPONI, Sandra. Da Compaixão à Solidariedade. Uma genealogia da assistência médica. 1. ed. Rio de Janeiro: Fiocruz, 2004. ISBN 85-85676-88-4

CAPONI, Sandra. Classificar e medicar: A gestão biopolítica dos sofrimentos psíquicos. Separata de: CAPONI, Sandra; VALENCIA, María Fernanda Vásquez; VERDI, Marta; ASSMANN, Selvino José (org.). A medicalização da vida como estratégia biopolítica. 1. ed. São Paulo: LiberArs, 2013. p. 103-119. ISBN 978-85-64783-36-2.

CARRERO, Alexandra Mancera. Niños expósitos y menores en Bogotá: 1791-1920. Nómadas, n. 36, p. 225-237, 2012. Disponible en: : https://www.redalyc.org/articulo.oa?id=105124264015. Accedido en 21 dic. 2020.

CASTEL, Robert. La inseguridad social. Buenos Aires: Manantial, 2011. 112 p. ISBN 978-987-500-078-0.

CASTILLO-GALLARDO, Patricia. Desigualdad e infancia: lectura crítica de la Historia de la Infancia en Chile y en América Latina. Revista Latinoamericana de Ciencias Sociales, Niñez y Juventud, v. 13, n. 1, p. 97-109, 2015. DOI 10.11600/1692715x.1314030214. Disponible en: 
http://www.scielo.org.co/pdf/rlcs/v13n1/v13n1a05.pdf. Accedido en 20 dic. 2020.

CONFERENCIAS DE BENEFICENCIA Y CORRECCIÓN (Cuba). Memoria oficial de la Segunda Conferencia Nacional de Beneficencia y Corrección de la Isla de Cuba 1903. 1. ed. La Habana: Imprenta La Moderna Poesía, 1904. 452 p.

CHAPLE, Enrique Beldarraín. Las instituciones y la salud pública en Cuba en la primera mitad del siglo XX. Diálogos: Revista Electrónica de Historia, San José, v. 15, n. 1, p. 175-191, 2014. Disponible en: https://revistas.ucr.ac.cr/index.php/dialogos/article/view/8373. Accedido en: 10 ene. 2020.

DUQUE, Matías. La prostitución, sus causas, sus males, su higiene. La Habana: IMPRENTA Y PAPELERÍA DE RAMBLA, B Q | 2 * Y COMPAÑÍA, 1914.

ENRIQUE, Martha Elizabeth Laguna. Vestigios de una necrópolis neoclásica: el Cementerio de Espada. Anales del Museo de América, [s. I.], n. 18, p. 192-211, 2010. Disponible en: https://www.researchgate.net/publication/277262261_Vestigios_de_una_nec ropolis_neoclasica_el_Cementerio_de_Espada. Accedido en: 30 ene. 2020.

FERNÁNDEZ, José Gregorio Cayuela. Un siglo de España: centenario 1898-1998. Castilla La Mancha: Universidad de Castilla La Mancha, 1998.

FOUCAULT, Michel. Power/knowledge: Selected Interviews and Other Writings 1972-1977. New York: Pantheon Books, 1980. ISBN 0-394-51357-6.

FOUCAULT, Michel. Estrategias de poder: Obras esenciales. 1. ed. Barcelona: Paidós, 1999. 203 p. v. II. ISBN 84-493-0695-7.

FOUCAULT, Michel. Vigiar e punir: Nascimento da prisão. 27. ed. Petrópolis: Vozes, 2003. 288 p. ISBN 85.326.0508-7.

FOUCAULT, Michel. Segurança, território e população. 1. ed. São Paulo: Martin Fontes, 2008. 295 p. ISBN 978-85-336-2377-4.

FOUCAULT, Michel. Em defesa da sociedade. 2. ed. São Paulo: Martins Fontes, 2018. 269 p. ISBN 978-85-7827-300-2.

GARCÍA, Antonio Santamaría. El crecimiento económico de Cuba republicana (1902-1959): Una revisión y nuevas estimaciones en perspectiva comparada (población, inmigración golondrina, ingreso no azucarero y producto nacional bruto). Revista de Indias, [s. I.], v. LX, n. 219, p. 505-545, 2000.

Disponible

en: http://revistadeindias.revistas.csic.es/index.php/revistadeindias/article/view/ 517. Accedido en: 10 ene. 2020. 
GOBIERNO Y CAPITANÍA GENERAL DE CUBA (Cuba). Miguel Tacón. 1838. Relación del Gobierno superior y Capitanía General de la Isla de Cuba, La Habana: Imprenta del Gobierno y Capitanía General, 1838. Disponible en: https://books.google.com.br/books?id=10uMvf3uUOEC\&printsec=frontcover \&hl=es\&source=glbs_ge_summary_r\&cad=0. Accedido en: 13 mayo 2020.

GONZAGA, Arthur Ramos. A Criança e a Periculosidade: a construção social da penalogia infantil no Brasil. Orientadora: Sandra Caponi. 2018. 212 p. Dissertação de mestrado (Mestre em Sociologia Política) Universidade Federal de Santa Catarina, Florianópolis, 2018. Disponible en: http://150.162.242.35/bitstream/handle/123456789/194466/PSOP0625-D.pdf? sequence=1\&isAllowed=y. Accedido: 21 dic. 2020.

HERNÁNDEZ, José Joaquín. El Mataperros. In: BUENO, Salvador (org.). Costumbristas cubanos del siglo XIX. Caracas: Biblioteca Ayacucho, 1958. p. 161-165. ISBN 84-660-0123-9.

LOPEZ, Ricardo. Historia de Cuba. Historia (Santiago), Santiago, v. 43, n. 1, p. 271-282, jun. 2010. Disponible en <https://scielo.conicyt.cl/scielo.php?script=sci_arttext\&pid=S0717-719420100 o0100016\&lng=es\&nrm=iso>. Accedido en 22 agosto 2020. http://dx.doi.org/10.4067/s0717-71942010000100016.

MARTÍNEZ, Yolanda Díaz. De marginados a trabajadores. Usos y destinos de la población penal en La Habana. Millars, Castellón de la Plana, v. XXXV, p. 129-149, $2012 . \quad$ Disponible en: https://dialnet.unirioja.es/servlet/articulo?codigo=4126645. Accedido en: 29 jul. 2020.

MÉNDEZ, Emilio García. Derecho de la infancia-adolescencia en América Latina: de la situación irregular a la protección integral. Bogotá: Fórum Pacis, 1994.

MITJAVILA, Myriam. O risco como recurso para a arbitragem social. Tempo soc., São Paulo, v. 14, n. 2, p. 129-145, Oct. 2002. Disponible en: <http://www.scielo.br/scielo.php?script=sci_arttext\&pid=S0103-20702002000 200007\&lng=en\&nrm=iso>. Accedido en: 10 agosto 2020. https://doi.org/10.1590/S0103-20702002000200007.

MORENO, Reinier Borrego. La nación desvalida. Pobreza y beneficencia pública en Cuba (1899-1930). Temas, La Habana, n. 84, p. 54-62, oct/dic 2015.

MORENO, Reinier Borrego. Mataperros entre esclavos y libres "de color". Revista de Historia de las Prisiones, [s. I.], n. 4, p. 60-91, ene/jul 2017. Disponible en: www.revistadeprisiones.com , uploads , 2017/05 , 3.mataperros.pdf. Accedido en: 15 enero 2020. 
NÚÑEZ, Yoel Cordoví. Cuerpo, pedagogía y disciplina escolar en Cuba: dispositivos de control desde los discursos higienistas (1899 - 1958). TZINTZUN Revista de Estudios Históricos, Michoacán, n. 56, 2012. Disponible en: http://www.scielo.org.mx/pdf/tzintzun/n56/n56a3.pdf. Accedido en: 3 agosto 2020.

ORTIZ, Medardo German Castro. ¿Niños delincuentes? Fundamentos de su punibilidad en el derecho penal moderno. Orientador: Yisel Boza Cruz. 2011. 88 f. Trabalho de Conclusão de Curso (Licenciatura en Derecho) Universidad Técnica de Cotopaxi, Ecuador, 2011. Disponible en: http://repositorio.utc.edu.ec/bitstream/27000/923/1/T-UTC-0657.pdf.

Accedido en: 6 feb. 2020.

PADILLA, Antonio Arroyo. Escuelas especiales a finales del siglo XIX. Una mirada a algunos casos en México. Revista Mexicana de Investigación Educativa, México, v. 3, n. 5, 1998. Disponible en: https://dialnet.unirioja.es/servlet/articulo?codigo=300279. Accedido en: 19 dic. 2020.

PEÑA, J.M. La legislación y la escuela correccional para varones. Separata de: CONFERENCIA NACIONAL DE BENEFICENCIA Y CORRECCIÓN DE LA ISLA DE CUBA (La Habana). Memoria oficial de la Segunda Conferencia Nacional de Beneficencia y Corrección de la Isla de Cuba 1903. 1. ed. La Habana: Imprenta La Moderna Poesía, 1904. p. 216-226.

RAMÍREZ, Antonio Guzmán. Valoración de la educación en el territorio nororiental de Cuba durante la República (1902-58). Luz, Holguín, v. 8, n. 2, 2009. Disponible en: https://luz.uho.edu.cu/index.php/luz/article/view/432. Accedido en: 10 ene. 2020.

RODRÍGUEZ, Alicia Conde. Pensamiento pedagógico cubano 1902-1920: Crítica y conciencia en la República. 2. ed. La Habana: Ciencias Sociales, 2018. ISBN 978-959-06-2058-4.

SACO, José Antonio. La vagancia en Cuba: Vigencia de Saco. ESTENGER, Rafael (ed.). La Habana: Ministerio de Educación, Dirección de Cultura, 1946. $135 \mathrm{p}$.

SIERRA, Félix Santularia. Las "Casas de Corrección" en el siglo XIX español. (Notas para su estudio). Historia de la educación, Salamanca, n. 18, p. 93-109, $1999 . \quad$ Disponible en: https://www.researchgate.net/publication/39148259_Las_casas_de_correccio n_en_el_siglo_XIX_espanol_notas_para_su_estudio. Accedido en: 29 jul. 2020.

STAGNO, Leandro. La minoridad en la Provincia de Buenos Aires, 1930-1943: ideas punitivas y prácticas judiciales. 2008. Tesis de posgrado. Facultad Latinoamericana de Ciencias Sociales (FLACSO). Sede Académica 
VALDÉS, Gerónimo. Bando de gobernación y policía de la isla de Cuba. [s.l] Impr. del Gobierno y Capitanía General por SM,1842.

VALDÉS, Juan B. Protección al niño. Separata de: CONFERENCIA NACIONAL DE BENEFICENCIA Y CORRECCIÓN DE LA ISLA DE CUBA (La Habana). Memoria oficial de la Segunda Conferencia Nacional de Beneficencia y Corrección de la Isla de Cuba 1903. 1. ed. La Habana: Imprenta La Moderna Poesía, 1904. p. 35-43.

VÁZQUEZ, María Osta. Niños y Niñas, expósitos y huérfanos en Montevideo del siglo XIX. Rev. Fac. Der., Montevideo, Uruguay, n. 41, p. 155-189, dez. 2016. DOI $10.22187 / \mathrm{rfd} 201627$. http://www.scielo.edu.uy/scielo.php?script=sci_arttext\&pid=\$2301-066520160 00200007\&lng=es\&nrm=iso. Accedido en: 20 dic. 2020.

ZAMORA, M.D. La regeneración del niño por los trabajos agrícolas. Escuelas agrícolas. Separata de: CONFERENCIA NACIONAL DE BENEFICENCIA Y CORRECCIÓN DE LA ISLA DE CUBA. (La Habana). Memoria oficial de la Segunda Conferencia Nacional de Beneficencia y Corrección de la Isla de Cuba 1903. 1. ed. La Habana: Imprenta La Moderna Poesía, 1904. p. 45-52.

ZANELLA, Maria Nilvane. A implantação do menorismo na América Latina no início do século XX: tendências jurídicas e políticas para a contenção dos mais pobres. Revista Ibero-Americana de Estudos em Educação, v. 14, n. 3, 2019. DOI 10.21723/riaee.v14iesp.3.12761. Disponible en: https://periodicos.fclar.unesp.br/iberoamericana/article/view/12761. Accedido en: 19 dic. 2020. 